\title{
STUDY OF SERUM AMINOTRANSFERASE LEVELS IN DENGUE FEVER
}

\author{
Jnaneshwari $\mathrm{M}^{1}$, Jayakumar $\mathrm{S}^{2}$, Arun Kumar³ ${ }^{3}$ Uday $\mathrm{G}^{4}$
}

\section{HOW TO CITE THIS ARTICLE:}

Jnaneshwari M, Jayakumar S, Arun Kumar, Uday G. "Study of Serum Aminotransferase Levels in Dengue Fever". Journal of Evolution of Medical and Dental Sciences 2014; Vol. 3, Issue 10, March 10; Page: 2445-2455, DOI: $10.14260 /$ jemds/2014/2157

ABSTRACT: BACKGROUND: The involvement of liver in dengue fever is not uncommon as reported in literature since 1970. Liver and nervous system involvement simultaneously predicts poor outcome in dengue fever. Atypical manifestations include liver involvement with elevation of enzymes, central nervous involvement (encephalopathy) and cardiac alterations (myocarditis). Liver involvement in dengue fever is manifested by the elevation of transaminases representing reactive hepatitis, due to direct attack of virus itself or the use of hepatotoxic drugs. OBJECTIVE OF THE STUDY: Study of serum aminotransferase levels in dengue fever. METHODOLOGY: In this descriptive, cross sectional study, all patients who presented to the Department of medicine with dengue IgM positive were included. Study period of 24 months from July 2010-June 2012, patients attending to M.S. Ramaiah medical college were included ( $n=166)$. RESULTS: 166 patients reactive for dengue virus specific IgM antibody were studied. As per WHO classification, 137 (82.5\%) patients were classified as dengue fever, $20(12 \%)$ as dengue hemorrhagic fever, and $9(5.4 \%)$ as dengue shock syndrome. Mean age of dengue infection patients was $35.71 \pm 12.9$ (SD) years, with male to female ratio nearly equal. Hepatic dysfunction is very common in all forms of dengue infection, with AST rising significantly more than ALT. Serum aminotransferase levels appear to have a directly proportional correlation with grading of dengue infection. Hyperbilirubinemia, elevated transaminases, hypoproteinemia, hypoalbuminemia and deranged coagulation profile were seen in higher frequency in DHF and DSS group as compared to classical DF group. AST and ALT were significantly higher in patients with secondary infection (IgM \& IgG positive) as compared to primary infection (IgM positive). CONCLUSION: Serum aminotransferase levels are significantly raised in all forms of dengue infection and it directly correlates with severity of infection. Serum aspartate aminotransferase was significantly raised compared to alanine aminotransferase levels in all forms of dengue infection. The degree of affection of serum albumin and prothrombin time which are absolute indicators of liver cell function correlated with severity of dengue infection.

KEYWORDS: Dengue fever - DF, Dengue Hemorrhagic Fever -DHF, Dengue Shock Syndrome-DSS. Alanine aminotransferase - ALT. Aspartate aminotransferase - AST.

INTRODUCTION: Dengue infection, an arthropod-borne viral hemorrhagic fever, continues to be a major challenge to public health, especially in South-East Asia. ${ }^{1}$ It has a wide geographical distribution and can present with a diverse clinical spectrum. ${ }^{2}$ Dengue fever is one of the world's most common viral hemorrhagic fever disease, most geographically widespread of the arthropodborne virus illnesses. Caused by arbovirus of Flavivirus genus with 4 serotypes. It is transmitted by Aedes aegypti, Aedes albopictus. 4 spectra of illness are seen; an asymptomatic phase, acute febrile illness, classic Dengue fever (DF), Dengue Hemorrhagic Fever (DHF) which includes Dengue Shock Syndrome (DSS). Dengue viral infection has been recognized as one of the world's biggest emerging epidemics. Throughout the tropics this infection has an annual incidence of 100 million cases of DF 
with another 2, 50, 000 cases of DHF and mortality rate of 24000-25000 per year. Although dengue virus is a non hepatotropic virus, liver injury due to dengue infection is not uncommon and has been described since the 1960 s. $^{3}$

Hepatic involvement can be characterized by manifestations of acute hepatitis, with pain in the right hypochondrium, hepatomegaly, jaundice, and raised aminotransferase levels. In hepatitis, the levels of these enzymes reach a maximum on the ninth day after the onset of symptoms, and they gradually return to normal levels within three weeks. Although the liver is not the main target organ for this disease, histopathological findings, including centrilobular necrosis, fatty alterations, hyperplasia of the Kupffer cells, acidophil bodies and monocyte infiltration of the portal tract have been detected in patients with dengue hemorrhagic fever (DHF) and dengue shock syndrome (DSS). In most cases, hepatic involvement prolongs the clinical course of this self-limiting viral infection, but it does not constitute a sign of worse prognosis. The liver dysfunction could be a direct viral effect or an adverse consequence of dysregulated host immune response against the virus. ${ }^{4}$ Several outbreaks of dengue infection have been reported from India. However, large clinical studies documenting hepatic involvement in dengue infection, especially in adults, are scarce.

AIMS AND OBJECTIVES: The aim of this study was to assess the serum aminotransferase levels in patients with dengue infection presenting to a tertiary-care medical facility.

MATERIAL AND METHOD: The study was performed on patients admitted for dengue fever in this descriptive, cross sectional study; all patients who presented to the Department of medicine with dengue IgM positive were included. Study period of 24 months from July 2010-June 2012, patients attending to M.S.Ramaiah medical college, Bangalore were included ( $\mathrm{n}=166)$.

\section{INCLUSION CRITERIA:}

- Dengue IgM positive.

\section{EXCLUSION CRITERIA:}

-Age <18 years, -Malaria,

-Typhoid, -Leptospirosis,

-History of alcohol abuse. -Chronic liver disease,

-Viral hepatitis (Hepatitis A, Hepatitis B, Hepatitis C).

All patients were evaluated with detailed history including age, sex, presenting symptoms; history of co morbid illness; alcohol consumption and use of hepatotoxic drugs were noted.

The World Health Organization (WHO) grading system was used to classify patient as having classic dengue fever (DF) and dengue hemorrhagic fever (DHF) (WHO, 1997). ${ }^{2}$ DHF was defined as fever with thrombocytopenia (platelet count less than $100,000 / \mathrm{mm}^{3}$ ) and evidence of plasma leakage as manifested by either an increase in hematocrit of $\geq 20 \%$ during the course of hospitalization or a rise in hematocrit to more than $20 \%$ of baseline (average normal hematocrit ratio for males: 0.45 and for females: 0.38) DHF was graded as DHF grade 1 (DHF-1, no spontaneous hemorrhage) and DHF grade 2 (DHF-2, with spontaneous hemorrhage). 
Dengue shock syndrome (DSS) was diagnosed if patient fulfilled criteria for DHF along with signs of shock as manifested by rapid and weak pulse, narrowing of pulse pressure, or hypotension (DHF-3); those with profound shock with unrecordable blood pressure and pulse were classified as DHF-4. Vitals parameters and systemic examination were done. The following investigations were done with special emphasis.

Dengue Serology: Done by immunochromatographic method.

Liver Function Test: AST and ALT was estimated by IFCC (International Federation of Clinical Chemistry) without pyridoxal phosphate activation. Total bilirubin, total protein, albumin and ALP were estimated by colorimetric assay.

Routine investigations: Hemoglobin percentage, total count, ESR, Packed cell volume (PCV), Platelet count, PT and APTT, blood urea, serum creatinine, and blood sugar estimation was done.

Statistical Analysis: Descriptive statistical analysis has been carried out in the present study. Results on continuous measurements are presented on Mean \pm SD (Min-Max) and results on categorical measurements are presented in Number (\%). Analysis of variance (ANOVA) has been used to find the significance of study parameters between three or more groups of patients, Chi-square/ Fisher Exact test has been used to find the significance of study parameters on categorical scale between two or more groups.

+ Suggestive significance ( $\mathrm{P}$ value: $0.05<\mathrm{P}<0.10$ )

$*$ Moderately significant ( $\mathrm{P}$ value: $0.01<\mathrm{P} \leq 0.05$ )

** Strongly significant ( $\mathrm{P}$ value: $\mathrm{P} \leq 0.01$ )

Statistical Software: The Statistical software namely SAS 9.2, SPSS 15.0, Stata 10.1, MedCalc 9.0.1, Systat 12.0 and R environment ver.2.11.1 were used for the analysis of the data and Microsoft word and Excel have been used to generate graphs, tables etc.

RESULTS: Table 1 shows 166 Dengue IgM positive patients were included in the study after they had fulfilled the inclusion and exclusion criteria. Of 166 patients reactive for dengue virus specific $\operatorname{IgM}$ antibody, dengue virus-specific IgG antibody was also positive in 41 (24.71\%) patients. As per WHO classification, 137 (82.5\%) patients were classified as dengue fever, $20(12 \%)$ as dengue hemorrhagic fever, and $9(5.4 \%)$ as dengue shock syndrome.

Further, 24.8\% (34/137) patients with DF, 10\% (2/20) patients with DHF, and 55.5\% (5/9) patients with DSS had positive IgG antibody, indicating sequential infection.

Mean age of dengue infection patients was 35.71 12.9 (SD) years. Maximum number of patients were seen in the age group of $21-30$ years i.e. 57 pt (34.2\%) and 43 patients $(25.8 \%)$ were in age group of 31-40 year. The study group included 86 males and 80 females, with male to female ratio nearly equal.

The main presenting symptoms were fever which was present in all patients (100\%), headache in 134patients (80.7\%), myalgia in 90 patients (54.2\%), arthralgia in 88patients (53\%), hemorrhagic manifestations in 77patients (46.4\%), vomiting in 67patients (40.4\%) and abdominal pain in 45 patients $(27.1 \%)$.

Table 2 shows bleeding gums was the most common site of hemorrhage ( $n=36 / 166,21.7 \%)$, followed by skin rash/ petechiae $(n=24 / 166,14.5 \%)$. 
Table 3 shows fever and headache was present in all the dengue subgroups. Occurrence of retro-orbital pain, arthralgia, myalgias, vomiting, pain abdomen and hemorrhagic manifestation were statistically significant in DHF and DSS compared to classical Dengue fever patients.

Table 4 shows hepatic dysfunction, in the form of raised total bilirubin values was present in $31.2 \%(52 / 166)$, raised direct bilirubin in 62.6\% (104/166), decreased total protein in 37.8\% (63/166), hypoalbuminaemia in 40.3\% (67/166), raised AST in 99.3\% (165/166), raised ALT in 96.6\% (161/166) and raised ALP in 68.2\% (114/166) patients. AST levels were $270.63 \pm 255.33 \mathrm{U} / \mathrm{L}$ and were significantly higher than ALT levels (166.21 $\pm 167.28 \mathrm{U} / \mathrm{L})$ and ALP levels (126.38 \pm 65.63$)$.

Table 5 and 6 shows comparison between the mean values of liver function tests in different dengue subgroups is shown in Hyperbilirubinemia, elevated transaminases, hypoproteinaemia, and hypoalbuminaemia were seen in higher frequency in DHF and DSS as compared to classical DF.

Table 7 show the elevation in transaminases level in different dengue subtypes. Most patients had modest elevation of liver enzymes in dengue subgroups. Liver dysfunction was more severe in DHF and DSS. Two patients had AST levels more than 10 times the upper normal limit in DHF. Patients with DSS had significantly elevated AST levels and ALT levels more than 10 times. (Since the AST/ALT, the SD is more, the Student t test is not applicable hence, non- parametric test, Mann Whitney U test has been used. Nature of parameters produces the more Standard deviation.)

Table 8 shows hyperbilirubinemia, hypoproteinaemia, hypoalbuminaemia, elevated transaminases and deranged coagulation profile was mostly associated with patients who had hemorrhagic manifestation as compared to those without.

Table 9 shows it was noted that AST and ALT were significantly higher in patients with secondary infection (IgM \& IgG positive) as compared to primary infection.

Table 10 shows comparison of the DF and DHF groups, it was observed that the mean value of pulse was significantly different in the two groups whereas pulse, blood pressure and respiratory rate were significantly more deranged in the DSS group as compared to the DF group. PCV was significantly increased in DHF and DSS group when compared to DF group. ESR and platelet count was significantly more deranged in the DHF group as compared to the DF group. PT and APTT were significantly deranged in DSS and DHF patients as compared to DF group.

OUTCOME: All patients recovered from dengue infection in DF and DHF groups, 3 patients died in dengue shock syndrome group.

DISCUSSION: The biochemical impact of dengue virus on liver function was studied in 166 serologically confirmed cases of dengue IgM infection. In this study, DHF and DSS were present in $12 \%(20 / 166)$ and $5.4 \%(9 / 166)$ patients respectively. This is as with the results of a recent study from Punjab done by Rajoo et al ${ }^{5}$ (DHF and DSS in 13.6\% and 5.1\% respectively) and from Delhi done by Makroo et $\mathrm{al}^{6}$ (DHF and DSS in 9.3\% and 2.2\% respectively). However a few other studies had reported a higher percentage of DHF.7,8

The mean age of patients in our study was $35.71 \pm 12.9$ years, with male to female ratio being near equal. In a recent study done by Rajoo et al. ${ }^{5}$ mean age was 31.6 years with a range of 15 to 80 years, with predominant male patients (male: female ratio $=3.3: 1$ ).

Jaundice in dengue infection has been associated with fulminant liver failure and by itself is a poor prognostic factor. ${ }^{9}$ In our study hyperbilirubinemia was significantly more common in patients 
with DSS and DHF when compared to DF patients with or without hemorrhage. Rajoo et al. ${ }^{5}$ found Hyperbilirubinemia to be significantly more common in patients with DSS, DF patients with hemorrhage and in non-survivors. Thus, observations support the fact that high bilirubin may act as a bad prognostic marker in patients with dengue infection. ${ }^{5}$

Hepatomegaly was observed in $11.4 \%$ patients in this study, compared to $12.1 \%$ in Rajoo et al. ${ }^{5}$ and $17.6 \%-20.4 \%$ in other Indian studies. ${ }^{7,} 10$ The relative higher incidence of hepatomegaly reported by Sharma et al. ${ }^{10}$ could be attributed to the fact that all their patients belonged to the DHF group. Although liver size does not correlate with disease severity, an enlarged liver is observed more frequently in shock than in non-shock cases. ${ }^{1}$ In our study, too, hepatomegaly was more frequent in the DSS group as compared to DF group (55.5 \%; 5/9 v/s 7.2\%; 10/137).

Biochemical liver dysfunction, in the form of increased transaminases, was found in most of the patients in our study $96.6 \%$ - 99.3\%, similar to the results of Rajoo et al. ${ }^{5}(93.9 \%-97.7 \%)$ and other studies. ${ }^{7,8,10,11}$ However, in a study by Souza et al. ${ }^{12}$ AST and ALT were deranged only in $63.4 \%$ and $45 \%$ patients respectively. In our study, increased levels of ALP and serum bilirubin were noted in a smaller proportion of patients, as with the results of Rajoo et al. ${ }^{5}$ and Itha et al. ${ }^{8}$

The aspartate aminotransferase (AST) levels in dengue infection tend to be greater than alanine aminotransferase (ALT) levels. ${ }^{13,14}$ In our study too, aspartate aminotransferase (AST) levels $(270.63 \pm 255.33 \mathrm{U} / \mathrm{L})$ tend to be greater than alanine aminotransferase (ALT) levels $(166.21 \pm 167.28$ $\mathrm{U} / \mathrm{L}$ ). This pattern is similar to that we see in alcoholic hepatitis but differs from that seen in other viral hepatitis. The exact cause of this is uncertain, but it has been suggested that it may be due to excess release of AST from damaged myocytes during dengue infection. ${ }^{11}$ This preferential elevation of liver enzymes, with AST being significantly higher than ALT was also noted in study done by Rajoo et al. ${ }^{5}$ This abnormality may act as an early indicator of dengue infection. Comparing the three subgroups of dengue infection (DF, DHF and DSS), it was observed that the frequency of liver dysfunction (raised AST, ALT and ALP) was equally common in all the groups (Table 5 and 6). Similar results were noted in Itha et al. ${ }^{8}$

However, Wahid et al. ${ }^{15}$ found liver dysfunction to be more common in DHF than in DF patients. The severity of hepatic dysfunction in dengue infection has been associated with disease severity. Indeed, liver injury has been proposed to be a good positive predictive factor for the development of DHF.14 We noted a greater degree of hepatic injury in the DHF \& DSS group (significantly deranged liver parameters) as compared to the DF group, suggesting that the degree of liver injury may be related to the severity of dengue infection. Similar data have been suggested by Souza et al. ${ }^{12}$ However, in two other studies, the degree of elevation of liver enzymes in the DF and DHF groups was not significantly different. 8,15

In our study, the mean bilirubin, AST, ALT, total protein, albumin and coagulation profile values were significantly deranged in patients with hemorrhage as compared to those without. Rajoo et al ${ }^{5}$ observed that the mean bilirubin, ALT and ALP values were significantly higher in patients with hemorrhage as compared to those without hemorrhage, and were even higher in those with GI hemorrhage. Wahid et al. ${ }^{15}$ also observed that the ALT and ALP levels were significantly higher in DHF patients with spontaneous bleeding than those without bleeding $(\mathrm{p}<0.05)$, while Nguyen et al. ${ }^{9}$ noted significantly higher elevation of AST and ALT in DHF patients with gastrointestinal hemorrhage. A possible reason for this could be an ischemic injury to the liver due to hypotension. 
Table 12 shows in the present study, AST and ALT levels were significantly higher in patients with sequential dengue infection as compared to those with primary infection. Rajoo et al 5 observed that the mean bilirubin, ALT and ALP values were significantly higher in patients with sequential dengue infection as compared to those with primary infection, while the mean AST value in the two groups was similar. Nguyen et $\mathrm{al}^{9}$ observed that the results of transaminases did not differ significantly between the two groups, while Souza et al ${ }^{6}$ noted that transaminases were significantly higher in cases with sequential infection.

Patients with DHF and DSS had significantly raised PT and APTT values in our study. Rajoo et al ${ }^{5}$ observed increased percentage of patients with deranged PT index significantly more in the DSS group as compared to the DF group.

Serum aminotransferase elevation is seen in all patients with dengue infection, directly correlating with severity of infection.

Limitation of the study is Ns1Ag (non-structural protein) test could not be done due to nonavailability of kit during the study period.

CONCLUSION: Serum aminotransferase levels are significantly raised in all forms of dengue infection and it directly correlates with severity of infection. Serum aspartate aminotransferase was significantly raised compared to alanine aminotransferase levels in all forms of dengue infection.

The degree of affection of serum albumin and prothrombin time which are absolute indicators of liver cell function correlated with severity of dengue infection.

SUMMARY: Hepatic dysfunction is very common in all forms of dengue infection, with AST rising significantly more than ALT. A greater degree of hepatic injury is observed in DHF group and DSS group as compared to the DF group. Serum bilirubin, AST, ALT and coagulation profile are significantly deranged in patients with hemorrhage as compared to those without. AST and ALT are significantly higher in patients with sequential infection. Serum aminotransferase levels appear to have a directly proportional correlation with grading of dengue. Bleeding gums was the most common form of bleeding manifestation observed in dengue patients.

\section{REFERENCES:}

1. WHO: Dengue Hemorrhagic Fever: Diagnosis, Treatment and Control, Geneva, World Health Organization, 1997.

2. Gubler DJ. Dengue. In: Monath TP, ed. The Arboviruses: Epidemiology and Ecology, Boca Raton: CRC Press; 1988:223-260.

3. Gubler DJ. Dengue and dengue hemorrhagic fever: its history and resurgence as a global public health problem. In: Gubler DJ, Kuno G, ed. Dengue and Dengue Hemorrhagic Fever, Willingford: CAB International; 1997:1-22.

4. Rico-Hesse R. Molecular evolution and distribution of dengue virus type 1 and type 2 in nature. Virology 1990; 174:479-493.

5. Rajoo Singh Chhina, Omesh Goyal, Deepinder Kaur Chhina, Prerna Goyal, Raj Kumar, Sandeep Puri. Liver function tests in patients with dengue viral infection. Dengue Bulletin, 2008; Volume 32:110-117. 
6. Makroo RN, Raina V, Kumar P, Kanth RK. Role of platelet transfusion in the management of dengue patients in a tertiary care hospital. Asian J Transfus Sci. 2007; 1(1): 4-7.

7. Daniel R, Rajamohanan, Philip AZ. A study of clinical profile of dengue fever in Kollam, Kerala, India. Dengue Bulletin. 2005; 29:197-202.

8. Itha S, Kashyap R, Krishnani N, Saraswat VA, Choudhuri G, Aggarwal R. Profile of liver involvement in dengue virus infection. Natl Med J India. 2005; 18(3): 127-130.

9. Nguyen TL, Nguyen NT, Tieu NT. The impact of dengue fever on liver function. Res Virol, 1997; 148(4): 273-277.

10. Sharma S, Sharma SK. Clinical profile of DHF in adults during 1996 outbreak in Delhi, India. Dengue Bulletin. 1998; 22: 20-27.

11. Kuo C.H, Tai D.I, Chang-Chien C.S, Lan C.K, Chiou S.S, Liaw Y.F. Liver biochemical tests and dengue fever. Am J Trop Med Hyg 1992; 47, 265-270.

12. Souza L.J, Alves J.G, Nogueira R.M.R, Neto C.G, Bastos D.A, da Siva Siqueira E.W, Souto Filho J.T.D, Cezario T.A, Soares C.E, Carneiro R.C. Aminotransferase changes and acute hepatitis in patients with dengue fever: analysis of 1585 cases. Braz J Infect Dis. 2004; 8, 156-163.

13. Souza LJ, Gonçalves Carnerio H, Souto Filho JT, Souza TF, Cortes VA, Neto CG, Bastos DA, Siqueira EWS. Hepatitis in dengue shock syndrome. Braz J Infect Dis. 2002; 6(6):322-327.

14. Kalayanarooj S, Vaughn DW, Nimmannitya S, Green S, Suntayaorn S, Kunentrasai N, Viramitrachai W, Ratanachu-eke S, Kiatpolpoj S, Innis BL, Rothman AL, Nisalak A, Ennis FA. Early clinical and laboratory indicators of acute dengue illness. J Infect Dis. 1997; 176(2): 313321.

15. Wahid S.F, Sanus S, Zawawi M.M, Ali R.A. A comparison of the pattern of liver involvement in dengue hemorrhagic fever with classic dengue fever. Southeast Asian J Trop Med Public Health, 2000; 31, 259-263.

\begin{tabular}{|c|c|c|c|c|}
\hline Diagnosis & $\begin{array}{c}\text { Number } \\
\text { of patients } \\
\text { IgM Positive }\end{array}$ & $\mathbf{\%}$ & $\begin{array}{c}\text { Number } \\
\text { of patients } \\
\text { IgG Positive }\end{array}$ & $\%$ \\
\hline Dengue fever (DF) & 137 & 82.5 & 34 & 24.8 \\
\hline Dengue Hemorrhagic Fever (DHF) & 20 & 12.0 & 2 & 10 \\
\hline Dengue Shock Syndrome (DSS) & 9 & 5.4 & 5 & 55.5 \\
\hline Total & $\mathbf{1 6 6}$ & $\mathbf{1 0 0 . 0}$ & $\mathbf{4 1}$ & \\
\hline
\end{tabular}

Table 1: Diagnosis of dengue infection

\begin{tabular}{|c|c|c|}
\hline $\begin{array}{c}\text { Hemorrhagic } \\
\text { manifestation }\end{array}$ & $\begin{array}{c}\text { Number of } \\
\text { patients }(\mathbf{n = 1 6 6 )}\end{array}$ & $\mathbf{\%}$ \\
\hline Absent & $\mathbf{8 9}$ & $\mathbf{5 3 . 6}$ \\
\hline Present & $\mathbf{7 7}$ & $\mathbf{4 6 . 4}$ \\
\hline$\bullet \quad$ Bleeding gums & 36 & 21.7 \\
\hline$\bullet \quad$ Petechiae/Rash & 24 & 14.5 \\
\hline$\bullet \quad$ Erythematous rash & 7 & 4.2 \\
\hline$\bullet \quad$ Ecchymosis & 6 & 3.6 \\
\hline
\end{tabular}


ORIGINAL ARTICLE

\begin{tabular}{|c|c|c|}
\hline - $\quad$ Menstrual bleeding & 2 & 1.2 \\
\hline - $\quad$ Epistaxis & 2 & 1.2 \\
\hline
\end{tabular}

Table 2: Hemorrhagic manifestations

\begin{tabular}{|l|c|c|c|c|}
\hline \multirow{2}{*}{ Variables } & \multicolumn{3}{|c|}{ Diagnosis } & \multirow{2}{*}{ 'p' value } \\
\cline { 2 - 5 } & $\begin{array}{c}\text { DF } \\
(\mathbf{n = 1 3 7 )}\end{array}$ & $\begin{array}{c}\text { DHF } \\
(\mathbf{n = 2 0 )}\end{array}$ & $\begin{array}{c}\text { DSS } \\
\text { (n=9) }\end{array}$ & \\
\hline 1) Fever & $137(100 \%)$ & $20(100 \%)$ & $9(100 \%)$ & 1.000 \\
\hline 2) Headache & $111(81 \%)$ & $14(70 \%)$ & $9(100 \%)$ & $0.075+$ \\
\hline 3) Retro-orbital pain & $17(12.4 \%)$ & $9(45 \%)$ & $2(22.2 \%)$ & $0.004^{* *}$ \\
\hline 4) Arthralgia & $63(46 \%)$ & $16(80 \%)$ & $9(100 \%)$ & $<0.001^{* *}$ \\
\hline 5) Myalgia & $66(48.2 \%)$ & $15(75 \%)$ & $9(100 \%)$ & $<0.001^{* *}$ \\
\hline 6) Vomiting & $46(33.6 \%)$ & $16(80 \%)$ & $5(55.6 \%)$ & $<0.001^{* *}$ \\
\hline 7) Pain abdomen & $25(18.2 \%)$ & $14(70 \%)$ & $6(66.7 \%)$ & $<0.001^{* *}$ \\
\hline 8) Hemorrhagic manifestation & $48(35 \%)$ & $20(100 \%)$ & $9(100 \%)$ & $<0.001^{* *}$ \\
\hline
\end{tabular}

Table 3: Symptomatology in dengue subgroups

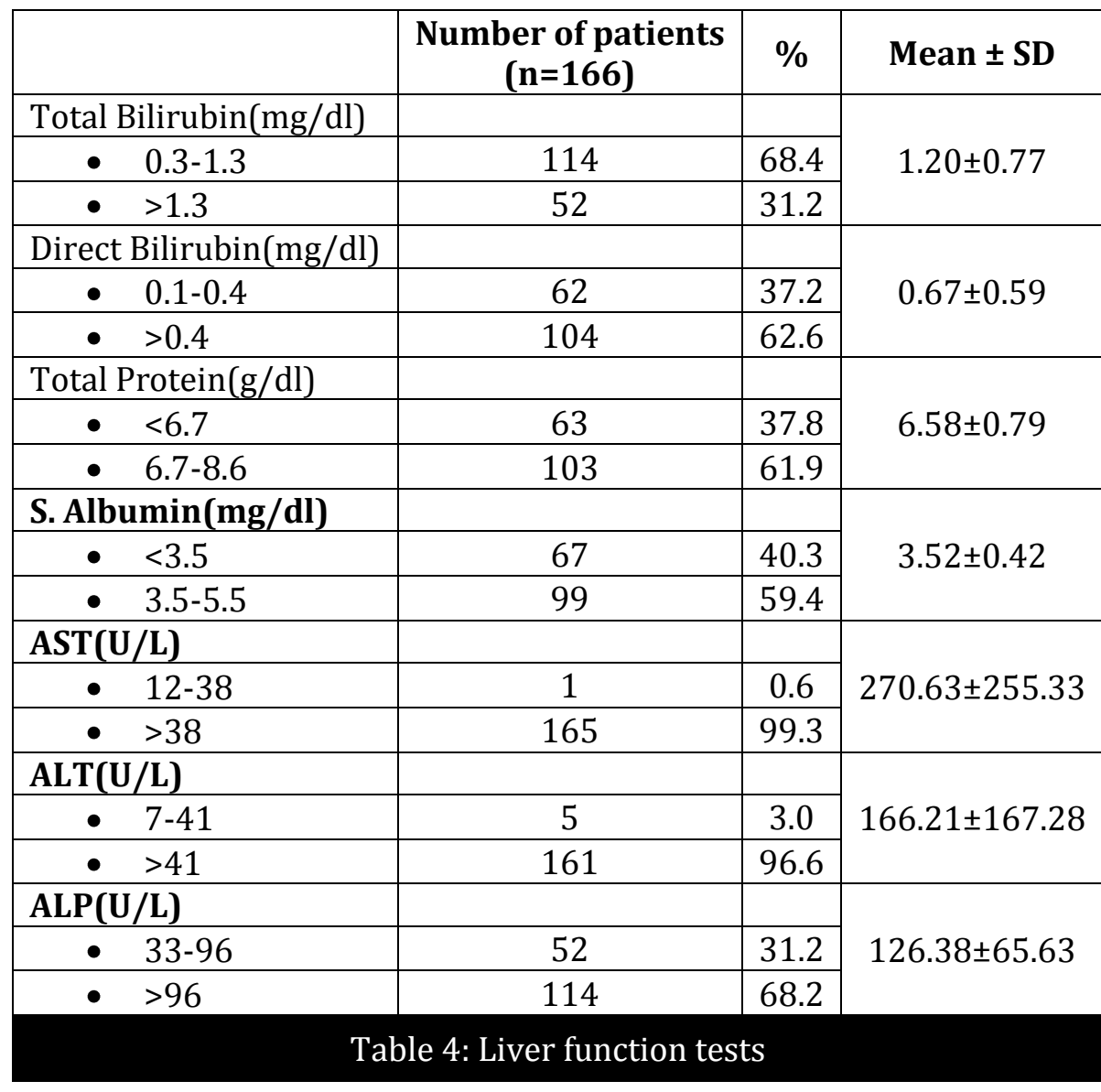


ORIGINAL ARTICLE

\begin{tabular}{|l|c|c|c|}
\hline \multicolumn{1}{|c|}{ Variables } & $\begin{array}{c}\text { DF } \\
(\mathbf{n = 1 3 7 )}\end{array}$ & $\begin{array}{c}\text { DHF } \\
\mathbf{( n = 2 0 )}\end{array}$ & 'p' value \\
\hline Total Bilirubin & $0.95 \pm 0.37$ & $1.78 \pm 0.30$ & $<0.001^{* *}$ \\
\hline Direct Bilirubin & $0.49 \pm 0.24$ & $0.95 \pm 0.29$ & $<0.001^{* *}$ \\
\hline Total protein & $6.87 \pm 0.52$ & $5.21 \pm 0.13$ & $<0.001^{* *}$ \\
\hline Albumin & $3.61 \pm 0.40$ & $3.31 \pm 0.19$ & $0.003^{* *}$ \\
\hline AST & $201.78 \pm 76.76$ & $351.02 \pm 84.02$ & $<0.001^{* *}$ \\
\hline ALT & $123.4 \pm 49.65$ & $186 \pm 43.65$ & $0.004^{* *}$ \\
\hline ALP & $116.08 \pm 53.6$ & $146.33 \pm 95.26$ & $0.088+$ \\
\hline
\end{tabular}

Table 5: Comparison of liver function tests in dengue subgroups

\begin{tabular}{|l|c|c|c|}
\hline \multicolumn{1}{|c|}{ Variables } & $\begin{array}{c}\text { DF } \\
(\mathbf{n = 1 3 7 )}\end{array}$ & $\begin{array}{c}\text { DSS } \\
\mathbf{( n = 9 )}\end{array}$ & 'p' value \\
\hline Total Bilirubin & $0.95 \pm 0.37$ & $3.82 \pm 0.33$ & $<0.001^{* *}$ \\
\hline Direct Bilirubin & $0.49 \pm 0.24$ & $2.86 \pm 0.24$ & $<0.001^{* *}$ \\
\hline Total protein & $6.87 \pm 0.52$ & $5.17 \pm 0.12$ & $<0.001^{* *}$ \\
\hline Albumin & $3.61 \pm 0.40$ & $2.71 \pm 0.14$ & $<0.001^{* *}$ \\
\hline AST & $201.78 \pm 76.76$ & $1140.22 \pm 528.85$ & $<0.001^{* *}$ \\
\hline ALT & $123.4 \pm 49.65$ & $774.11 \pm 287.49$ & $<0.001^{* *}$ \\
\hline ALP & $116.08 \pm 53.6$ & $237.67 \pm 39.49$ & $<0.001^{* *}$ \\
\hline
\end{tabular}

Table 6: Comparison of liver function tests in dengue subgroups

\begin{tabular}{|c|c|c|c|c|}
\hline \multirow[b]{2}{*}{ Variables } & \multicolumn{3}{|c|}{ Diagnosis } & \multirow[b]{2}{*}{ 'p' value } \\
\hline & $\begin{array}{c}\text { DF } \\
(n=137)\end{array}$ & $\begin{array}{c}\text { DHF } \\
(n=20)\end{array}$ & $\begin{array}{c}\text { DSS } \\
(n=9)\end{array}$ & \\
\hline \multicolumn{5}{|l|}{ AST(0 - $42 \mathrm{U} / \mathrm{L})$} \\
\hline - $\quad<1$ ULN & $2(1.5 \%)$ & $0(0 \%)$ & $0(0 \%)$ & \multirow{4}{*}{$<0.001^{* *}$} \\
\hline - $1-3 \mathrm{ULN}$ & $28(20.4 \%)$ & $0(0 \%)$ & $0(0 \%)$ & \\
\hline - 3-10 ULN & $107(78.1 \%)$ & $18(90 \%)$ & $0(0 \%)$ & \\
\hline - $\quad>10$ ULN & $0(0 \%)$ & $2(10 \%)$ & $9(100 \%)$ & \\
\hline \multicolumn{5}{|l|}{ ALT (0 - $48 \mathrm{U} / \mathrm{L})$} \\
\hline - $\quad<1$ ULN & $7(5.1 \%)$ & $0(0 \%)$ & $0(0 \%)$ & \multirow{4}{*}{$<0.001^{* *}$} \\
\hline - $1-3$ ULN & $64(46.7 \%)$ & $0(0 \%)$ & $0(0 \%)$ & \\
\hline - 3-10 ULN & $66(48.2 \%)$ & $20(100 \%)$ & $1(11.1 \%)$ & \\
\hline - $\quad>10$ ULN & $0(0 \%)$ & $0(0 \%)$ & $8(88.9 \%)$ & \\
\hline \multicolumn{5}{|l|}{ ALP 20 - 125 U/L } \\
\hline - $<1$ ULN & $98(71.5 \%)$ & $12(60 \%)$ & $0(0 \%)$ & \multirow{3}{*}{$<0.001^{* *}$} \\
\hline - $1-2$ ULN & $34(24.8 \%)$ & $7(35 \%)$ & $6(66.7 \%)$ & \\
\hline - $>2$ ULN & $4(2.9 \%)$ & $1(5 \%)$ & $3(33.3 \%)$ & \\
\hline
\end{tabular}

Table 7: Comparison of liver enzymes in dengue subgroups 


\begin{tabular}{|l|c|c|c|}
\hline \multirow{2}{*}{ Liver function test } & \multicolumn{2}{|c|}{ Hemorrhagic Manifestations } & \multirow{2}{*}{ 'p' value } \\
\cline { 2 - 3 } & No & Yes & \\
\hline Total bilirubin & $0.93 \pm 0.36$ & $1.52 \pm 0.98$ & $<0.001^{* *}$ \\
\hline AST & $202.21 \pm 78.78$ & $349.73 \pm 350.06$ & $<0.001^{* *}$ \\
\hline ALT & $125.28 \pm 51.57$ & $213.54 \pm 231.19$ & $0.001^{* *}$ \\
\hline ALP & $120.34 \pm 62.76$ & $133.46 \pm 68.59$ & 0.202 \\
\hline Total protein & $6.85 \pm 0.56$ & $6.26 \pm 0.91$ & $<0.001^{* *}$ \\
\hline S Albumin & $3.62 \pm 0.43$ & $3.42 \pm 0.40$ & $0.002^{* *}$ \\
\hline PT & $11.41 \pm 0.82$ & $13.74 \pm 2.14$ & $0.003^{* *}$ \\
\hline APTT & $30.39 \pm 2.54$ & $42.56 \pm 12.02$ & $0.006^{* *}$ \\
\hline
\end{tabular}

Table 8: Comparison of LFT levels with hemorrhagic manifestations

\begin{tabular}{|l|c|c|c|}
\hline \multirow{2}{*}{ Liver function test } & \multicolumn{2}{|c|}{ Dengue serology } & \multirow{2}{*}{ 'p' value } \\
\cline { 2 - 3 } & $\begin{array}{c}\text { IgM } \\
\text { positive only }\end{array}$ & $\begin{array}{c}\text { IgG and IgM } \\
\text { Positive }\end{array}$ & \\
\hline Total bilirubin & $1.17 \pm 0.68$ & $1.32 \pm 1.00$ & 0.271 \\
\hline AST & $247.16 \pm 166.28$ & $342.21 \pm 419.82$ & $0.038^{*}$ \\
\hline ALT & $149.67 \pm 116.83$ & $216.66 \pm 263.94$ & $0.026^{*}$ \\
\hline ALP & $124.95 \pm 67.39$ & $130.72 \pm 60.60$ & 0.627 \\
\hline Total protein & $6.57 \pm 0.80$ & $6.61 \pm 0.79$ & 0.770 \\
\hline S Albumin & $3.54 \pm 0.42$ & $3.47 \pm 0.46$ & 0.325 \\
\hline
\end{tabular}

Table 9: Comparison of Liver function test in primary and secondary infection

\begin{tabular}{|l|c|c|c|c|c|}
\hline \multicolumn{1}{|c|}{ Variables } & $\begin{array}{c}\text { DF } \\
(\mathbf{n = 1 3 7 )}\end{array}$ & $\begin{array}{c}\text { DHF } \\
\mathbf{( n = 2 0 )}\end{array}$ & 'p' value & DSS (n=9) & 'p' value \\
\hline Age in years & $36.23 \pm 13.78$ & $32.9 \pm 7.54$ & 0.530 & $34.00 \pm 6.63$ & 0.870 \\
\hline Temperature $(\mathrm{oF})$ & $98.02 \pm 7.70$ & $98.6 \pm 0.00$ & 0.938 & $99.73 \pm 0.98$ & 0.761 \\
\hline Pulse (beats/min) & $79.97 \pm 9.71$ & $86.2 \pm 11.70$ & $0.026^{*}$ & $108.44 \pm 9.32$ & $<0.001^{* *}$ \\
\hline SBP (mm of Hg) & $117.46 \pm 9.42$ & $119.4 \pm 13.61$ & 0.693 & $82.50 \pm 7.07$ & $<0.001^{* *}$ \\
\hline DBP (mm of Hg) & $74.96 \pm 6.54$ & $76 \pm 9.40$ & 0.803 & $62.22 \pm 4.41$ & $<0.001^{* *}$ \\
\hline RR (breath/min) & $18.20 \pm 2.30$ & $18.95 \pm 1.43$ & 0.321 & $20.67 \pm 1.41$ & $0.003^{* *}$ \\
\hline
\end{tabular}

Table 10: Comparison of clinical signs in DF subgroup

\begin{tabular}{|l|c|c|c|c|c|}
\hline \multicolumn{1}{|c|}{ Variables } & $\begin{array}{c}\text { DF } \\
(\mathbf{n = 1 3 7 )}\end{array}$ & $\begin{array}{c}\text { DHF } \\
(\mathbf{n = 2 0 )}\end{array}$ & 'p' value & $\begin{array}{c}\text { DSS } \\
\mathbf{( n = 9 )}\end{array}$ & 'p' value \\
\hline $\mathrm{Hb} \mathrm{gm} / \mathrm{dl}$ & $12.80 \pm 1.73$ & $13.03 \pm 2.08$ & 0.855 & $12.67 \pm 0.71$ & 0.972 \\
\hline PCV \% & $41.75 \pm 3.26$ & $47.08 \pm 3.69$ & $<0.001^{* *}$ & $47.36 \pm 4.39$ & $<0.001^{* *}$ \\
\hline ESR mm/hr. & $14.01 \pm 7.35$ & $21.85 \pm 10.42$ & $<0.001^{* *}$ & $14.89 \pm 5.18$ & 0.941 \\
\hline Platelet/mm ${ }^{3}$ & $37167.58 \pm 30363.2$ & $19272 \pm 17881.91$ & $0.025^{*}$ & $15000 \pm 3815.43$ & $0.063+$ \\
\hline PT (in sec.) & $12.02 \pm 1.09$ & $15.57 \pm 0.76$ & $<0.001^{* *}$ & $16.77 \pm 0.54$ & $<0.001^{* *}$ \\
\hline APTT (in sec.) & $33.43 \pm 3.02$ & $48.84 \pm 4.88$ & $<0.001^{* *}$ & $66.51 \pm 5.15$ & $<0.001^{* *}$ \\
\hline
\end{tabular}

Table 11: Comparison of Laboratory parameters in dengue subgroups 


\begin{tabular}{|c|c|c|c|c|}
\hline Variables & Our study & Rajoo et al.[87] & Daniel R.[89] & Sharma S. [91] \\
\hline No. of Patients & 166 & 214 & 250 & 98 \\
\hline Age(Mean \pm SD)yrs. & $35.71 \pm 12.9$ & $31.6 \pm$ & $42.6 \pm 20$ & $26.3 \pm 10$ \\
\hline M: F ratio & Equal & $3.3: 1$ & Equal & $3: 1$ \\
\hline DF & $137(82.5 \%)$ & $174(81.3 \%)$ & $166(66.4 \%)$ & _ \\
\hline DHF & $20(12 \%)$ & $29(13.6 \%)$ & \multirow[b]{2}{*}{$\sqrt{84}(33.6 \%)$} & $75(76.5 \%)$ \\
\hline DSS & $9(5.4 \%)$ & $11(5.1 \%)$ & & $23(23.4)$ \\
\hline Hemorrhagic manifestation & $77(46.4 \%)$ & $40.6 \%$ & $15.2 \%$ & $56.1 \%$ \\
\hline Platelet count & $33809 \pm 29183$ & $48500 \pm 2600$ & $108(47.4 \%)$ & $30000 \pm 25000$ \\
\hline Hepatomegaly & $19(11.4 \%)$ & $26(12.1 \%)$ & $44(17.6 \%)$ & $20(20.4 \%)$ \\
\hline T. Bilirubin & $1.2 \pm 0.77$ & $0.93 \pm 0.09$ & $>2 \mathrm{mg} / \mathrm{dl}-9 \%$ & $0.9 \pm 0.6$ \\
\hline S. albumin & $3.52 \pm 0.42$ & $3.2 \pm 0.04$ & - & - \\
\hline AST (U/L) & $270.6 \pm 255.3$ & $353.7 \pm 49.6$ & $>250$ in $84 \%$ & $274 \pm 634$ \\
\hline $\operatorname{ALT}(\mathrm{U} / \mathrm{L})$ & $166.2 \pm 167.2$ & $218.6 \pm 27.2$ & - & $143 \pm 242$ \\
\hline $\operatorname{ALP}(\mathrm{U} / \mathrm{L})$ & $126.3 \pm 65.6$ & $135.2 \pm 6.5$ & - & $196 \pm 155$ \\
\hline
\end{tabular}

\section{AUTHORS:}

1. Jnaneshwari M.

2. Jayakumar S.

3. Arun Kumar.

4. Uday G.

\section{PARTICULARS OF CONTRIBUTORS:}

1. Senior Resident, Department of General Medicine, ESIC MC \& PGIMSR.

2. Senior Resident, Department of General Medicine, ESIC MC \& PGIMSR.

3. Senior Resident, Department of General Medicine, ESIC MC \& PGIMSR.

4. Senior Resident, Department of General Medicine, ESIC MC \& PGIMSR.

\section{NAME ADDRESS EMAIL ID OF THE} CORRESPONDING AUTHOR:

Dr. Jayakumar S,

No. U - 14, $7^{\text {th }}$ Cross,

Dayananda Nagar, Sri Rampuram,

Bangalore - 560021, Karnataka.

E-mail: jaykumar.blue24@gmail.com

Date of Submission: 04/02/2014.

Date of Peer Review: 05/02/2014.

Date of Acceptance: 17/02/2014.

Date of Publishing: 04/03/2014. 